\title{
К ОТДЕЛЬНЫМ ВОПРОСАМ ПОЛУЧЕНИЯ КОММЕРЧЕСКОЙ ТАЙНЫ ПРИ ОСУЩЕСТВЛЕНИИ АНТИМОНОПОЛЬНОГО КОНТРОЛЯ В РОССИИ И ЕС
}

\section{ON CERTAIN ISSUES OF OBTAINING COMMERCIAL SECRETS IN THE IMPLEMENTATION \\ OF ANTIMONOPOLY CONTROL IN RUSSIA AND THE EU}

S. Reshetnikova

Summary. Information is a unique intangible asset, since it can often have commercial value that is unprecedented in its importance for the entrepreneurial activity of an economic entity. The secret formulas of the company's bestsellers, schemes of unique inventions, databases of the largest customers and reliable counterparties, and even a marketing plan can provide a company with stable profits for a long time, but only if they remain confidential, inaccessible to third parties - competitors (including potential ones) and consumers.

Such information in legal science is covered by the concept of "commercial secret", the specific content of which differs in Russian law and the law of the European Union (hereinafter - "EU"), but essentially does not change.

This study will consider the issues of obtaining commercial secrets in the implementation of antitrust control in Russia and the EU.

Keywords: commercial secret, European Union, Russia, information, confidentiality.

\author{
Решетникова Стефания Борисовна \\ Аспирант, РАНХИГC \\ reshetnikovasb@gmail.com
}

Аннотация. Информация является уникальным нематериальным активом, поскольку зачастую может обладать коммерческой ценностью, беспрецендентной по своей значимости для предпринимательской деятельности хозяйствующего субъекта. Секретные формулы продуктов, являющихся бестселлерами компании, схемы уникальных изобретений, базы данных крупнейших клиентов и надежных контрагентов, и даже план маркетинговых активностей могут обеспечивать компании стабильную прибыль на протяжении длительного времени, но только в случае, если они остаются конфиденциальными, недоступными для третьих лиц конкурентов (в том числе потенциальных) и потребителей.

Такая информация в правовой науке охватывается понятием «коммерческая тайна», конкретное содержание которого разнится в российском праве и праве Европейского союза (далее — «ЕС»), но сущностно не меняется.

В данном исследовании будет рассмотрены вопросы получения коммерческой тайны при осуществлении антимонопольного контроля в России иEC.

Ключевые слова: коммерческая тайна, Европейский союз, Россия, информация, конфиденциальность.
$\mathbf{T}$ ак, термин «коммерческая тайна» закреплен в п. 1 ст. 3 Федерального закона от 29.07.2004 № 98-Ф3 «О коммерческой тайне», в соответствии с которым под коммерческой тайной понимается режим конфиденциальности информации, позволяющей ее обладателю при существующих или возможных обстоятельствах увеличить доходы, избежать неоправданных расходов, сохранить положение на рынке товаров, работ, услуг или получить иную коммерческую выгоду [1].

В Европейском союзе понятие «коммерческая тайна» было впервые определено Судом Правосудия делу Postbank NV v. Commission в 1996 году: «коммерческая тайна - это конфиденциальная информация о предпринимательской деятельности предприятия, раскрытие которой общественности, как и просто передача любому иному лицу, не являющемуся ее правообладателем, может нанести серьезный ущерб интересам последнего» [10].

В последующем термин был закреплен в ст. 2 Директивы Европейского парламента и Совета ЕС 2016/943 от 8 июня 2016 года о защите нераскрытых ноу-хау и деловой информации (коммерческой тайны) от их незаконного приобретения, использования и разглашения в следующем изложении: под коммерческой тайной понимается информация, которая отвечает всем следующим требованиям: (а) она является секретной, т.е. не является общеизвестной или легко доступной для лиц... которые обычно имеют дело с рассматриваемой информацией; (b) она имеет коммерческую ценность, поскольку является секретной; (c) в отношении 
нее правообладателем были приняты разумные меры по обеспечению ее конфиденциальности в данных обстоятельствах [6].

В силу особой ценности информации, составляющей коммерческую тайну, и во многих случаях ее определяющего воздействия на эффективность предпринимательской деятельности, хозяйствующие субъекты стремятся максимально обеспечить ее неприкосновенность, существенно ограничивая доступ к ней даже внутри компании, принимая все необходимые меры безопасности.

Тем не менее, в ряде случае компании должны предоставлять сведения, имеющие для них коммерческую значимость, третьим лицам, поскольку такая обязанность предусмотрена напрямую на законодательном уровне.

Так, ст. 25 Федерального закона о защите конкуренции предусмотрено, что хозяйствующие субъекты обязаны предоставлять по запросу ФАС России (в том числе в ходе проверки) в устной и письменной форме любые объяснения, документы и информацию, в том числе составляющие коммерческую тайну [2]. За непредставление информации по запросу антимонопольного органа хозяйствующие субъекты могут быть привлечены к ответственности по ч. 5 ст. 19.8 Кодекса об административных правонарушениях РФ.

При этом в ст. 26 Закона о защите конкуренции устанавливается, что антимонопольный орган обязан обеспечивать конфиденциальность полученной им от хозяйствующих субъектов охраняемой законом тайны, в том числе коммерческой тайны. За разглашение коммерческой тайны должностные лица антимонопольного органа несут ответственность.

Если рассмотреть эти нормы в системе, то можно сделать вывод от том, что таким образом законодатель постарался достичь баланса частных и публичных интересов: хозяйствующие субъекты обязаны в целях защиты публичных интересов раскрывать свою коммерчески ценную информацию, но при этом антимонопольный орган обязан конфиденциальность такой информации в целях защиты частных интересов соблюдать.

В ЕС применяется практически аналогичный подход.

Европейская комиссия, осуществляющая предупреждение и пресечение антиконкурентных практик на территории Европейского союза, также в соответствии с Регламентом ЕС № 1/2003 от 16 декабря 2002 года об осуществлении правил конкуренции, из- ложенных в статьях 81 и 82 ДФЕС (далее - Регламент № 1/2003) [5], наделена правом получения любой необходимой ей для исполнения своих функций информации посредством запросов о предоставлении информации и при осуществлении проверок соблюдения хозяйствующими субъектами антимонопольных правил Европейского Союза.

Европейская Комиссия, как и ФАС России, обязана обеспечить режим конфиденциальности полученной от хозяйствующих субъектов информации в соответствии со ст. 28 Регламента № 1/2003. Полученная Комиссией информация должна быть использована исключительно в целях антимонопольного расследования и не может быть разглашена третьим лицам. За уклонение от предоставления информации по запросу Европейской Комиссии хозяйствующие субъекты, как и в России, несут ответственность в форме штрафа в соответствии со ст. ст. 23, 24 Регламента № 1 /2003, кроме того непредставление информации может повлиять на размер итогового штрафа по антимонопольному делу.

Важно отметить, что и ФАС России, и Европейская Комиссия, при направлении запроса о получении необходимой для осуществления антимонопольного контроля информации, обязаны мотивировать такой запрос: указать нормы права, основываясь на которых антимонопольный орган направляет свой запрос; обозначить цель направления запроса и т.д.

В целом подходы к соблюдению баланса частных и публичных интересов при получении антимонопольными органами коммерческой тайны, механизмы обеспечения такого баланса и в России, и в ЕС схожи. Тем не менее, ЕС в данном вопросе явно на шаг впереди России: там в ходе правоприменительной практики были решены еще несколько очень важных для хозяйствующих субъектов проблем, связанных с получением коммерческой тайны и иной значимой конфиденциальной информации уполномоченными органами при осуществлении антимонопольного контроля.

Например, в ЕС третьи лица имеют право на сохранение конфиденциальности своей личности и представленных ими сведений, поскольку наличествует угроза дальнейшего применения в отношении них санкций доминирующим хозяйствующим субъектом, от которого информаторы находятся в экономической зависимости [9]. В России подобного механизма защиты информаторов, к сожалению, нет.

Еще один пример: в России, в соответствии со ст. 45.2 Закона о защите конкуренции, лица, участвующие в антимонопольном деле, могут получить доступ к коммерческой тайне других участников дела, представленной 
по запросу антимонопольного органа, только при наличии подтвержденного согласия таких участников дела - обладателей информации, содержащей коммерческую тайну. При этом в практике ЕС сформирован несколько иной подход, в соответствии с которым конфиденциальный характер информации не является препятствием для ее раскрытия в случаях, когда необходимость раскрытия конфиденциальной информации в целях реализации права на защиту одного лица обоснованно превышает необходимость обеспечения режима конфиденциальности информации другого лица.

Подводя итог изложенному, можно сделать вывод о том, что в целом антимонопольные органы и в РФ, и на уровне ЕС пытаются обеспечить соблюдение баланса частных и публичных интересов при получении ими коммерческой тайны. В то же время возникает ряд вопросов, касающихся достаточности таких механизмов, их оправданности, обоснованности обеспечения баланса интересов в том виде, в каком это имеет место в настоящее время. Данные вопросы имеют серьезное практическое значение. Хотя в настоящее время на законодательном уровне превалирует значимость государственных интересов в защите конкуренции, а высокий уровень соблюдения антимонопольным органом сохранности конфиденциальной информации презюмируется, представляется, что частные интересы хозяйствующих субъектов все же должны иметь чуть большую защиту, чем сейчас, если не на уровне законодательства, то хотя бы в контексте формирования правоприменительной практики, как это постарались сделать в Европейском Союзе.

\section{ЛИТЕРАТУРА}

1. Федеральный закон от 29.07.2004 № 98-Ф3 «0 коммерческой тайне» // Собрание законодательства РФ. — 2004. — № 32. — С. 3283.

2. Федеральный закон от 26 июля 2006 г. № 135-Ф3 «0 защите конкуренции» // Собрание законодательства РФ. — 2006. — № 31 (ч. І). - Ст. 3434 ; 2016. — № 27 (ч. I).— — (т. 4197.

3. BPB Industries и British Gypsum v. Commission [1993]. Case T-65/89 [Электронный ресурс] // Электронная правовая база EC. URL: https://europa.eu/!kc38Tc (Дата обращения 16.01.2021)

4. BPB Industries и British Gypsum v. Commission, EC: C: [1995]. Case C-310 / 93Р, [Электронный ресурс] // Электронная правовая база EC URL: https://еuropa. eu/! CB84Tw (Дата обращения 16.01.2021).

5. Council Regulation (EC) № 1/2003 of 16 December 2002 on the implementation of the rules on competition laid down in Articles 81 and 82 of the Treaty [Электронный ресурс] // Электронная правовая база EC. URL: https://eur-lex.europa.eu/legal-content/EN/TXT/HTML/?uri=CELEX:32003R0001 (Дата 06 ращения 15.01.2021).

6. Directive (EU) 2016/943 of the European Parliament and of the Council of 8 June 2016 on the protection of undisclosed know-how and business information (trade secrets) against their unlawful acquisition, use and disclosure [Электронный ресурс] // Электронная правовая база EC. URL: http://data.europa.eu/ eli/dir/2016/943/oj (Дата обращения 16.01.2021).

7. Joint Cases C-204/00 P, C-205/00 P, C-211/00 P, C-213/00 P, C-217/00 P and C-219/00 P Aalborg Portland and 0thers v. Commission [2004], параграфы 70-72 [Электронный ресурс] // Сайт Суда Европейского союза. URL: https://europa.eu/! HF79bu (Дата обращения 15.01.2021).

8. Michelin v. Commission [1983]. Case 322/81, параграфы 7 и 9 [Электронный ресурс] // Электронная правовая база EC. URL: https://europa.eu/! DX37gH (Дата обращения 16.01.2021).

9. Case T-65/89, BPB Industries и British Gypsum v. Commission [1993] [Электронный ресурс] // Электронная правовая база EC. URL: https://europa.eu/!kc38Tc (Дата обращения 16.01.2021); Case (-310 / 93Р, BPB Industries и British Gypsum v. Commission, EC: C: [1995] [Электронный ресурс] // Электронная правовая база EC URL: https://europa.eu/! CB84Tw (Дата обращения 16.01.2021).

10. Case T-353/94 Postbank NV v. Commission [1996], пункт 87. [Электронный ресурс] // Электронная правовая база EC. URL: https://europa.eu/!md76Np (Дата обращения 16.01.2021).

(c) Решетникова Стефания Борисовна ( reshetnikovasb@gmail.com ). Журнал «Современная наука: актуальные проблемы теории и практики» 